\title{
Adoção de biotecnologias para revegetação mais eficiente por feijão-de-porco e crotalária em rejeito de minério de ferro
}

\author{
Pedro Henrique Lopes Santana, Cássio Carlette Thiengo, Diego Lang Burak, Danilo Messias de Oliveira,
} Eduardo de Sá Mendonça

Universidade Federal do Espírito Santo - UFES, ES. E-mail: cassiocarlette@hotmail.com

\begin{abstract}
Resumo
Muitas vezes impossibilitadas de regeneração natural, áreas degradadas por rejeito de minério devem seguir medidas que visam sua recuperação ambiental. A revegetação e o uso de bioestimulantes podem contribuir com a melhoria da fertilidade do solo levando ao aumento da produção de biomassa vegetal e a ciclagem de nutrientes entre solo-planta. Objetivou-se avaliar a produção de matéria seca, o acúmulo e os índices de exportação de nutrientes por plantas de feijão-de-porco (Canavalia ensiformis) e Crotalaria juncea cv. IAC-KR-1 em função da aplicação de substâncias húmicas e bactérias diazotróficas. 0 experimento foi conduzido em casa de vegetação utilizando-se rejeito de minério de ferro como substrato. Foi empregado um delineamento experimental de blocos ao acaso $(4 \times 3 \times 2)$ com quatro repetições, sendo quatro doses de substâncias húmicas, aplicadas em 3 diferentes épocas, com ou sem inoculação de bactérias diazotróficas. $O$ fornecimento de substâncias húmicas e principalmente a inoculação em ambas espécies aumentaram a produção de matéria seca, atingindo $70 \%$ do incremento médio no feijão-de-porco. A inoculação em plantas de feijão-de-porco aumentou a absorção e fator de transferência de Fe e $P$, e reduziu o fator de transferência de $\mathrm{K}, \mathrm{Ca}$ e $\mathrm{Mg}$. Já nas plantas de crotalária, houve o aumento da absorção de $\mathrm{Mg}, \mathrm{P}$ e $\mathrm{Mn}$, e a redução da absorção de $\mathrm{Fe}$. $\mathrm{O}$ alto teor de Fe no rejeito de mineração culminou em grande absorção e mobilização deste elemento nas raízes das plantas como alternativa para minimizar efeitos tóxicos causados por seu excesso.
\end{abstract}

Palavras-chave: áreas degradadas; bioestimulantes; extração de nutrientes; bactérias diazotróficas; substâncias húmicas.

Adoption of biotechnologies for more efficient revegetation by jack beans and crotalaria in iron ore tailings

\begin{abstract}
Often unable to regenerate naturally, areas degraded by ore tailings must follow measures aimed at their environmental recovery. The revegetation and the use of bio-stimulants can contribute to the improvement of soil fertility leading to increased production of plant biomass and the cycling of nutrients between soil-plant. The objective was to evaluate the dry matter production, accumulation and nutrient export rates by pig bean plants (Canavalia ensiformis) and Crotalaria juncea cv. IAC-KR-1 as a function of the application of humic substances and diazotrophic bacteria. The experiment was conducted in a greenhouse using iron ore tailings as substrate. An experimental design of random blocks $(4 \times 3 \times 2)$ was used with four repetitions, four doses of humic substances, applied at 3 different times, with or without inoculation of diazotrophic bacteria. The supply of humic substances and mainly the inoculation in both species increased the dry matter production, reaching $70 \%$ of the average increase in pig beans. Inoculation in pig bean plants increased the absorption and transfer factor of $\mathrm{Fe}$ and $\mathrm{P}$, and reduced the transfer factor of $\mathrm{K}, \mathrm{Ca}$ and $\mathrm{Mg}$, and in crotalaria plants increased the absorption of $\mathrm{Mg}, \mathrm{P}$ and $\mathrm{Mn}$, and reduced the absorption of Fe. The high content of Fe in mining tailings culminated in high absorption and mobilization of this element in the roots of the plants as an alternative to minimize toxic effects caused by its excess.
\end{abstract}

Keywords: degraded areas; biostimulants; nutrient extraction; diazotrophic bacteria; humic substances. 


\section{Introdução}

A contaminação da bacia do Rio Doce caracterizou o maior desastre ambiental em terras brasileiras. Foram 60 milhões de metros cúbicos de rejeito oriundos da extração de minério de ferro, que percorreram cerca de 600 $\mathrm{km}$ atingindo sua foz em Linhares-ES. O rompimento das barragens localizadas no município de Mariana-MG afetou mais de 1500 ha, sobrepondo ao solo um material mineral de baixa fertilidade e com propriedades físicas que restringem o desenvolvimento vegetal (SCHAEFER et al., 2015). Nesse contexto, há a necessidade de minimizar os impactos ambientais nas áreas afetadas e de diminuir o aporte de sedimentos ao rio, sendo a revegetação o caminho para se iniciar o processo de recuperação ambiental (OLIVEIRA, 2014).

Recomenda-se que $O$ processo de revegetação seja iniciado com o cultivo de plantas rusticas que tolerem as restrições químicas, físicas e biológicas dos rejeitos de minério, além de contribuírem com incrementos no acúmulo de matéria orgânica para a estruturação do substrato, ciclagem de nutrientes e preparo do meio para sustentar espécies mais exigentes (ARAÚJO et al., 2005). O feijão-deporco e a crotalária são espécies da família Fabaceae que atendem a estas características, possuindo elevada capacidade adaptativa e reprodutiva (SILVA; CORRÊA, 2008) além de se associarem com bactérias que fixam nitrogênio $\left(\mathrm{N}_{2}\right)$, nutriente diretamente ligado ao ganho de matéria seca vegetal (HUNGRIA; NOGUEIRA, 2013).

Para aumentar a eficiência da técnica de revegetação em áreas degradadas, biotecnologias podem ser incorporadas com o objetivo de ampliar a produção de matéria seca pelas plantas. Dentre estas técnicas, a integração de bioestimulantes à base de bactérias diazotróficas e de substâncias húmicas representam estratégias promissoras, pela capacidade de estimular o desenvolvimento vegetal.

O nitrogênio $(N)$ é o macronutriente em maior concentração nos tecidos vegetais e escasso em áreas degradadas pela mineração, quando aplicado via fertilizantes sofre perdas pelos processos de lixiviação, desnitrificação e/ou volatilização. Desta forma, a fixação biológica de $\mathrm{N}$ por organismos que interagem com as plantas destaca-se, estimulando melhor desenvolvimento radicular e maior interação com o solo, permitindo maior absorção de água, nitrogênio atmosférico $\left(\mathrm{N}_{2}\right)$ e nutrientes (HUNGRIA et al., 2013). Por sua vez, as substâncias húmicas afetam positivamente $\mathrm{o}$ metabolismo das plantas, promovendo maior crescimento e maior eficiência na utilização de nutrientes (VACCARO et al., 2015).

Diante do exposto, o objetivo deste trabalho foi avaliar a produção de matéria seca, o acúmulo e os índices de exportação de nutrientes em plantas de feijão-de-porco e crotalária cultivadas em rejeito de minério de ferro em função da aplicação de substâncias húmicas e bactérias diazotróficas.

\section{Material e Métodos}

O experimento foi conduzido em casa de vegetação no Centro de Ciências Agrárias e Engenharias da Universidade Federal do Espírito Santo, campus de Alegre, ES, no período de janeiro a março de 2018, com temperatura controlada em 25ㅇ. .

O substrato utilizado foi um rejeito de minério de ferro, produto descartado nos processos de beneficiamento do minério de ferro, o qual após o rompimento das barragens de Fundão e Santarém, foi depositado na Usina Hidrelétrica Risoleta Neves, às margens do Rio Doce. O material foi coletado em diferentes pontos e apresentou atributos químicos e físicos dentro dos valores encontrados na literatura (SCHAEFER et al., 2015; SILVA et al., 2016). Amostras de rejeito foram secas ao ar livre e passadas em peneira de malha de $2 \mathrm{~mm}$ para determinação dos atributos químicos e físicos (Tabela 1) segundo metodologias preconizadas por Teixeira et al. (2017). 
Tabela 1. Atributos químicos e físicos do rejeito de minério de ferro utilizado no estudo, antes da aplicação dos tratamentos.

\begin{tabular}{|c|c|c|c|c|c|c|c|c|c|c|c|}
\hline $\mathrm{pH}$ & $\mathrm{Ca}^{2+}$ & $\mathrm{Mg}^{2+}$ & $\mathrm{H}+\mathrm{Al}$ & $\mathrm{Al}^{3+}$ & $\mathrm{Na}^{+}$ & $\mathbf{P}_{\text {disp }}$ & $\mathbf{K}^{+}$ & $\mathrm{Fe}_{\text {disp. }}$ & $\mathrm{Mn}_{\text {disp. }}$ & SB & $\mathbf{T}$ \\
\hline$\left(\mathrm{H}_{2} \mathrm{O}\right)$ & \multicolumn{4}{|c|}{-------cmol $\mathrm{dm}^{-3}$} & \multicolumn{5}{|c|}{--------------mg dm ${ }^{-3}$------------- } & \multicolumn{2}{|c|}{$\mathrm{cmolc} \cdot \mathrm{dm}^{-3}$} \\
\hline 6,95 & 0,68 & 0,46 & 0,66 & 0 & 4 & 8,72 & 9 & 88,6 & 30,8 & 1,18 & 1,84 \\
\hline $\mathbf{t}$ & $\mathbf{v}$ & $\mathbf{N}$ & \multicolumn{2}{|c|}{$\begin{array}{c}\text { C Orgânico } \\
\text { total }\end{array}$} & $\begin{array}{l}\text { Areia } \\
\text { fina }\end{array}$ & $\begin{array}{l}\text { Areia } \\
\text { grossa }\end{array}$ & Silte & Argila & Ds & Dp & Pt \\
\hline${ }_{3} \mathrm{cmolc} \mathrm{dm}^{-}$ & \multicolumn{2}{|l|}{$\%$} & \multicolumn{2}{|c|}{ dag $\mathrm{dm}^{-3}$} & & -------\% & 6-------- & & \multicolumn{2}{|c|}{$\mathrm{g} \mathrm{cm}^{-3}$} & $\%$ \\
\hline 1,18 & 64,06 & \multicolumn{3}{|c|}{--Não detectados -- } & 63,4 & 0,5 & 33,3 & 2,8 & 1,67 & 2,86 & 41,6 \\
\hline $\mathbf{P}$ & $\mathrm{K}$ & $\mathrm{Ca}$ & $\mathrm{Mg}$ & $\mathrm{Fe}$ & $\mathrm{Mn}$ & $\mathrm{S}$ & $\mathrm{Cu}$ & $\mathrm{Zn}$ & Mo & Cd & $\mathrm{Pb}$ \\
\hline \multicolumn{12}{|c|}{$\mathrm{mg} \mathrm{kg}^{-1}$} \\
\hline 72,7 & $5.283,3$ & 140,5 & 245,5 & $25.338,3$ & 260,2 & & \multicolumn{5}{|c|}{ 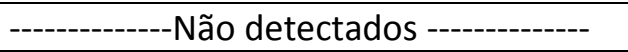 } \\
\hline \multicolumn{12}{|c|}{ 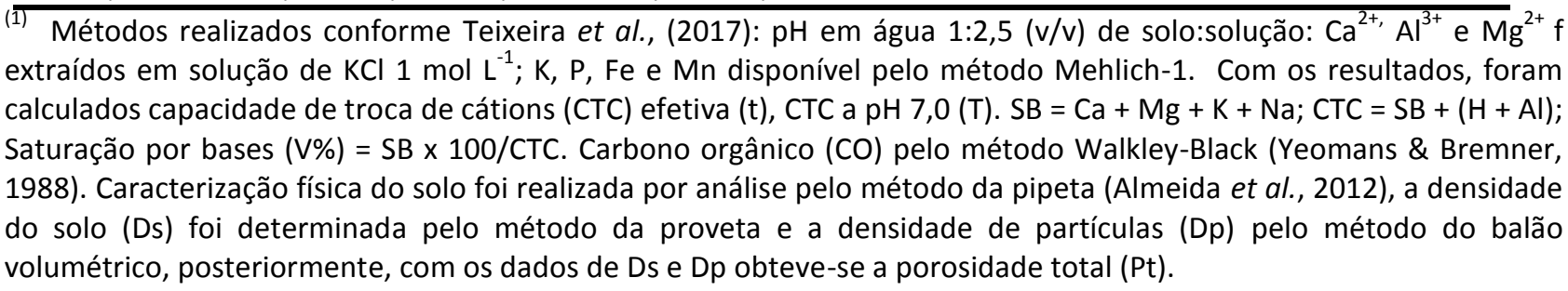 } \\
\hline
\end{tabular}

Foram cultivados feijão-de-porco (Canavalia ensiformes) e Crotalaria juncea cv. IAC-KR-1 em delineamento de blocos ao acaso, em esquema fatorial $4 \times 3 \times 2$ com quatro repetições, sendo quatro doses de substâncias húmicas (SH) via pulverização foliar [0; 30; 60 e $90 \mathrm{mg} \mathrm{L} \mathrm{L}^{-1}$ de $\left.\mathrm{C}_{\mathrm{SH}}\right]$, aplicadas em 3 diferentes épocas $(15,30$ ou 45 dias após emergência das plântulas (DAE)), com ou sem inoculação de bactérias diazotróficas, totalizando para cada espécie, 24 tratamentos e 96 unidades experimentais.

A adição de bactérias diazotróficas a partir do contato inóculo-semente ocorreu conforme metodologia preconizada pela Embrapa Agrobiologia (2009). As estirpes utilizadas (Rhizobium BR 2003) são da coleção de cultura da Embrapa Agrobiologia, em Seropédica, RJ. Após 5 dias de emergência das plântulas, ocorreu 0 transplantio em vasos plásticos de $4 \mathrm{dm}^{3}$ com o fundo vedado, procedimento este adotado para maior homogeneidade entre as mudas escolhidas.

A partir da curva característica de água do rejeito de minério em estudo, os vasos foram mantidos, a partir de pesagens diárias, em $50 \%$ da capacidade máxima de armazenamento de água do rejeito $\left(\Psi \mathrm{m}\right.$ de $\left.-0 \mathrm{kPa}=0,4160 \mathrm{~m}^{3} / \mathrm{m}^{3}\right)$. 0 controle da irrigação foi realizado com água purificada por osmose reversa.

As $\mathrm{SH}$ foram extraídas de vermicomposto comercial, produzido com esterco de curral utilizando-se água deionizada (1:9, v:v). Após seis horas de agitação, o material foi centrifugado e, posteriormente, ficou em repouso por 12 horas para que o sobrenadante fosse separado através de decantação e armazenado (MENDONÇA; MATOS, 2005). Foi determinado o teor de carbono (C) da solução com $\mathrm{SH}$, pois as concentrações utilizadas basearam-se no teor de C.

Após 66 dias do transplantio (início da floração), as plantas de feijão-de-porco e crotalária foram seccionada em parte aérea e raiz, em seguida secas em estufa $\left(65^{\circ} \mathrm{C}\right.$ por 72 horas) e pesadas, para obtenção da matéria seca da parte aérea (MSPA) e da raiz (MSR). Após triturado, realizou-se digestão nítrica em forno de micro-ondas utilizando-se $0,5 \mathrm{~g}$ de material vegetal e $10 \mathrm{~mL}$ de ácido nítrico ultrapuro. Os teores foram quantificado por espectrometria de emissão atômica com chama (K), espectrofotometria de absorção molecular UVVIS (P) e espectrometria de absorção atômica (Ca, $\mathrm{Mg}$, Fe e Mn).

Foram calculados o balanço de nutrientes (BN) no sistema que, posteriormente, foi convertido em \% do total estimado do rejeito (BN = acúmulo total de nutriente na planta do tratamento " $\mathrm{n}$ "/teor de nutriente no rejeito). Para avaliar o poder de extração de nutrientes foi realizado o cálculo do fator de transferência (FT = teor de nutriente na parte aérea do tratamento " $\mathrm{n}$ "/teor disponível de nutriente no rejeito). Por fim, foi obtido o índice de translocação (IT), que relaciona a mobilização do acúmulo de nutrientes 
na parte aérea e na raiz (IT = acúmulo de nutriente na parte aérea do tratamento " $n$ "/acúmulo de nutriente na raiz do tratamento "n").

Realizou-se testes de normalidade e homogeneidade de variância e se atendidas às pressuposições estatísticas, realizou-se análise de variância (ANOVA). Foi realizada análise de regressão para os fatores quantitativos, onde os modelos foram escolhidos com base na significância dos coeficientes de regressão utilizando-se o teste $t$ de Student ao nível de $5 \%$ de significância e o coeficiente de determinação $\left(R^{2}\right)$. Estatística descritiva, análise de variância e erro padrão foram utilizados para identificação dos efeitos dos tratamentos nos atributos não ajustado a regressões. Testes Tukey ao nível de 5 $\%$ de significância foram utilizados para algumas comparações destacadas no texto. As análises estatísticas foram realizadas pelo programa $R$ Development Core (Agricolae Package) (R CORE TEAM, 2016).

\section{Resultados e Discussão}

A produção de matéria seca da parte aérea por plantas de feijão-de-porco e crotalária cultivadas em rejeito de minério de ferro foi influenciada positivamente $(p<0,05)$ pela inoculação de bactérias diazotróficas (BD) (média feijão-de-porco $=6,99 \mathrm{~g} /$ planta - inoculadas; média feijão-de-porco $=5,88 \mathrm{~g} /$ planta - não-inoculadas; média crotalária $=1,06 \mathrm{~g} /$ planta - inoculadas; média crotalária $=0,76 \mathrm{~g} /$ planta - não-inoculadas). Estes resultados são semelhantes aos obtidos por Sala et al. (2007) e Rodrigues et al. (2014). Houve interação entre inoculação e as doses de substâncias húmicas (SH). Já o período de aplicação $(15,30$ ou 45 dias após transplantio), não apresentou efeito na maioria dos tratamentos. Ademais, os diferentes tratamentos promoveram alterações no crescimento de parte aérea e raiz destas plantas (Figura 1).

Figura1. Dados médios $(n=4)$ da matéria seca da parte aérea (MSPA) e de raízes (MSR) de plantas de feijãode-porco e crotalária com (A) ou sem inoculação de bactérias diazotróficas (B) e cultivadas em rejeito de minério de ferro em função da aplicação de diferentes doses de substâncias húmicas fornecidas aos 15,30 ou 45 dias após o transplantio (DAT).

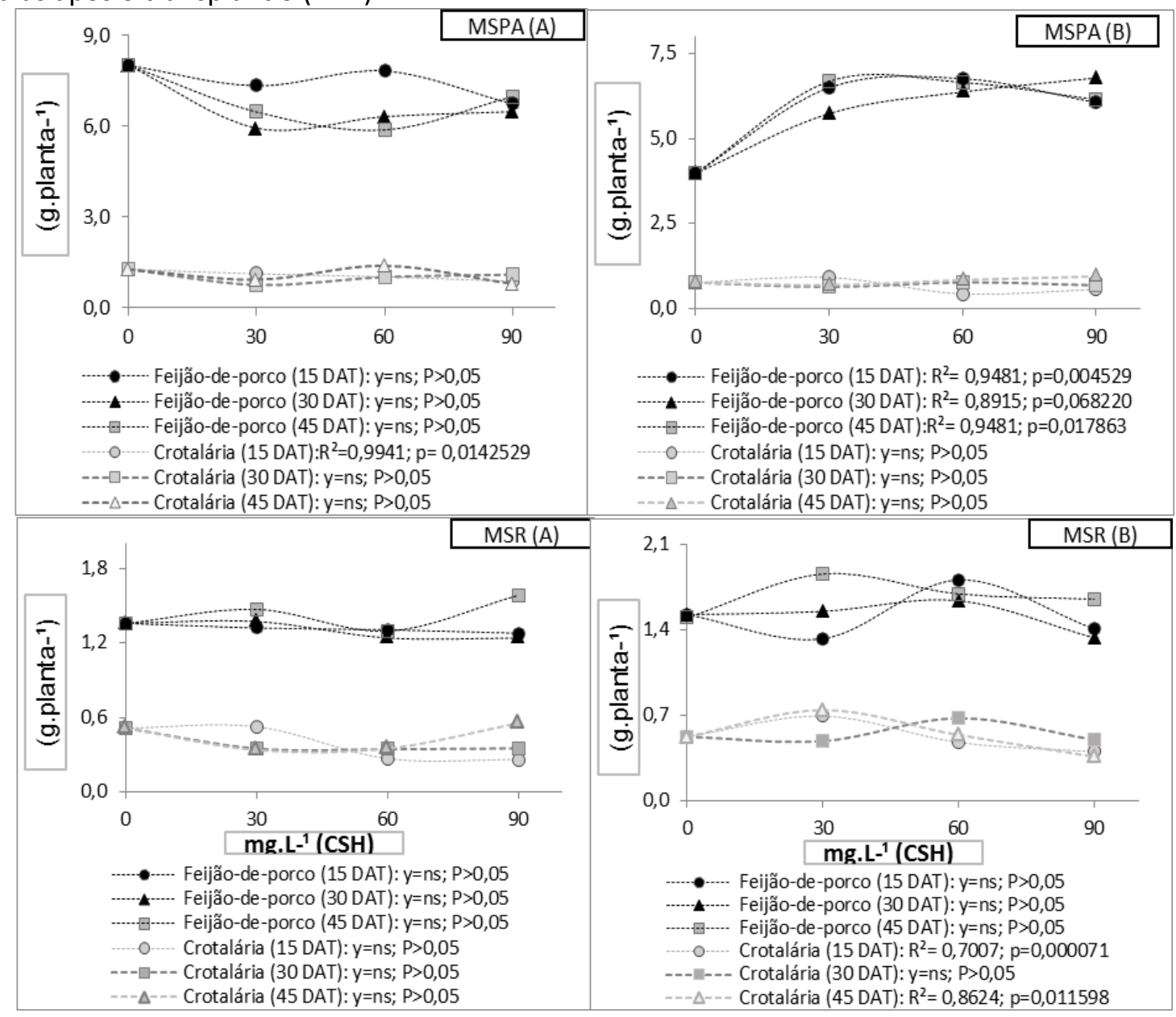


$\mathrm{O}$ fornecimento de $\mathrm{SH}$ em plantas inoculadas de ambos os tratamentos não promoveu aumento significativo no patamar de produção de matéria seca. Ademais, em plantas de crotalária inoculadas, as SH fornecidas aos 15 DAT reduziram linearmente a MSPA. Em relação às plantas de feijão-de-porco não inoculadas, a dose 60 fornecida aos 15 ou 45 DAT promoveram maior produção de MSPA (6,54 e 6,65 g/planta, respectivamente) e, quando as $\mathrm{SH}$ foram fornecidas aos 30 DAT, promoveram aumento linear da MSPA. Nesse contexto, fica claro que as pulverizações foliares de $\mathrm{SH}$ não causaram redução do crescimento vegetal por toxidez ou limitações à respiração celular das plantas (SILVA et al., 2016).

De acordo com Santos et al. (2013), o desenvolvimento radicular influencia nas características das plantas, como resistência ao déficit hídrico, ataque de pragas e eficiência na absorção de nutrientes do solo, sendo consideradas alterações positivas quando se pensa em revegetação de áreas ocupadas por rejeito de mineração, com escassez de nutrientes e baixo potencial de armazenar água. Para a MSR de plantas de crotalária não inoculadas, a dose 30 fornecida aos 15 ou 45 DAT promoveu maior produção de matéria seca (0,63 e 0,74 g/planta, respectivamente). Nos demais ajustes de regressão não foram verificados efeitos lineares ou quadráticos significativos da matéria seca em função das doses de SH fornecidas em diferentes épocas.

$\mathrm{O}$ que ocorreu com os tratamentos em que houve inoculação de BD e aplicação de SH pode estar relacionado ao fato da produção máxima de matéria seca pelo feijão-de-porco e de crotalária ser alcançada com o fornecimento de BD ou SH (independente da dose e época de aplicação).

Para os acúmulos de $\mathrm{N}, \mathrm{P}, \mathrm{K}, \mathrm{Ca}, \mathrm{Mg}$, Fe e Mn na parte aérea e raízes de feijão-de-porco e crotalária ocorreram diferenças significativas $(p<$
0,05 ) com os diferentes tratamentos (Figura 2). A ordem decrescente de acumulação de nutrientes na parte aérea do feijão-de-porco e crotalária foi: $\mathrm{N}>\mathrm{K}>\mathrm{Ca}>\mathrm{Mg}>\mathrm{Fe}>\mathrm{P}>\mathrm{Mn}$, resultados semelhantes $(\mathrm{N}>\mathrm{K}>\mathrm{Ca}>\mathrm{Mg}$ ) aos preconizados por Malavolta (1980), Neves et al. (2009) e Padovan et al. (2015) para plantas leguminosas. A alta disponibilidade de $\mathrm{Fe}$ no rejeito contribuiu para um maior acúmulo deste micronutriente em relação ao $\mathrm{P}$, pouco disponível.

$\mathrm{Na}$ distribuição relativa da matéria seca entre os componentes de ambas as plantas em estudo, observou-se que a maior porção foi alocada na parte aérea, desta forma, este componente apresentou os maiores acúmulos de $\mathrm{P}, \mathrm{K}, \mathrm{Ca}$ e $\mathrm{Mg}$ devido a demanda nutricional foliar para ocorrência de processos metabólicos (VIEIRA et al., 2013).

A baixa disponibilidade de $\mathrm{P}\left(8,72 \mathrm{mg} \mathrm{dm}^{-3}\right)$ e $\mathrm{K}$ (9 $\mathrm{mg} \mathrm{dm}^{-3}$ ) no rejeito de minério de ferro proporcionou baixo suprimento à parte aérea de ambas as plantas, inferior aos preconizados por Prezotti et al. (2007) como nível crítico para o desenvolvimento satisfatório das plantas. Os teores foliares médios $(\mathrm{mg} / \mathrm{kg})$ de nutrientes para o feijão de porco foram: $\mathrm{K}=484 \pm 154 ; \mathrm{Ca}=3077$ $\pm 530 ; \mathrm{Mg}=550 \pm 105 ; \mathrm{P}=209 \pm 51 ; \mathrm{Fe}=5.753 \pm$ 1.616 e $\mathrm{Mn}=228 \pm 54$, e para a crotalária: $\mathrm{K}=$ $6.139 \pm 1.658 ; \mathrm{Ca}=4.841 \pm 1.232 ; \mathrm{Mg}=1.795 \pm$ 493; $\mathrm{P}=794 \pm 226 ; \mathrm{Fe}=23.562 \pm 9.238$ e $\mathrm{Mn}=$ $223 \pm 99$.

Em relação às plantas de ambas as espécies que não receberam $\mathrm{SH}$, a inoculação promoveu maior acúmulo na parte aérea $(p<0,05)$ de $N, P$, $\mathrm{K}$ e Fe em plantas de feijão-de-porco, e de $\mathrm{P}, \mathrm{Ca}$, $\mathrm{Mg}$ e $\mathrm{Fe}$ em plantas de crotalária. Os maiores acúmulos de nutrientes promovidos pela inoculação podem estar associados ao sinergismo dos nutrientes com $\mathrm{O} \mathrm{NH}_{4}^{+}$que é mais disponibilizado apósa inoculação de BD (ORTEGA; MALAVOLTA, 2012). 
Figura 2. Dados médios $(n=4)$ do acúmulo de $N, P, K, C a, M g$, Fe e $M n$ na parte aérea (PA) de plantas de feijão-de-porco e crotalária com (A) ou sem inoculação de bactérias diazotróficas (B) e cultivadas em rejeito de minério de ferro em função da aplicação de diferentes doses de substâncias húmicas fornecidas aos 15 , 30 ou 45 dias após o transplantio (DAT).

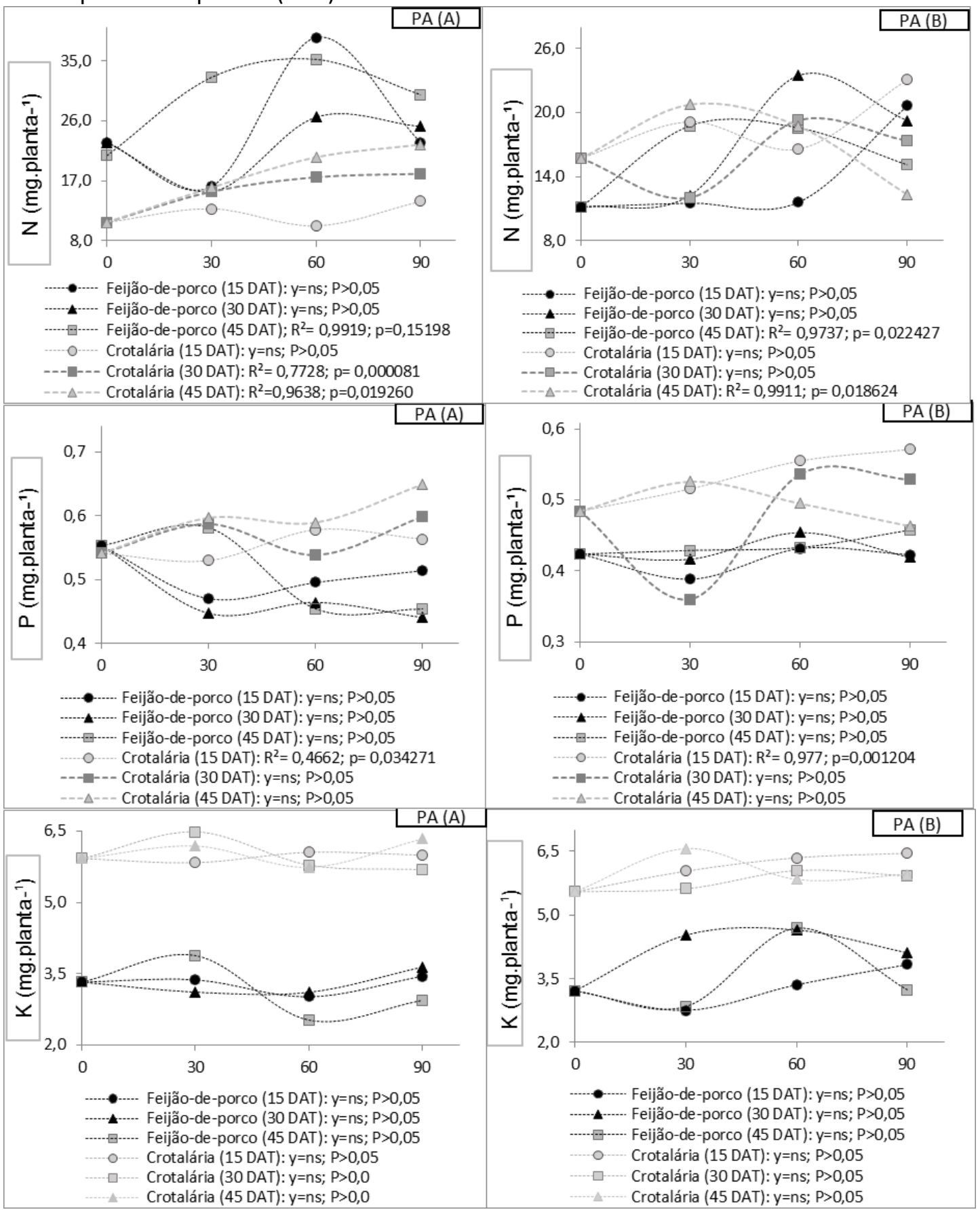




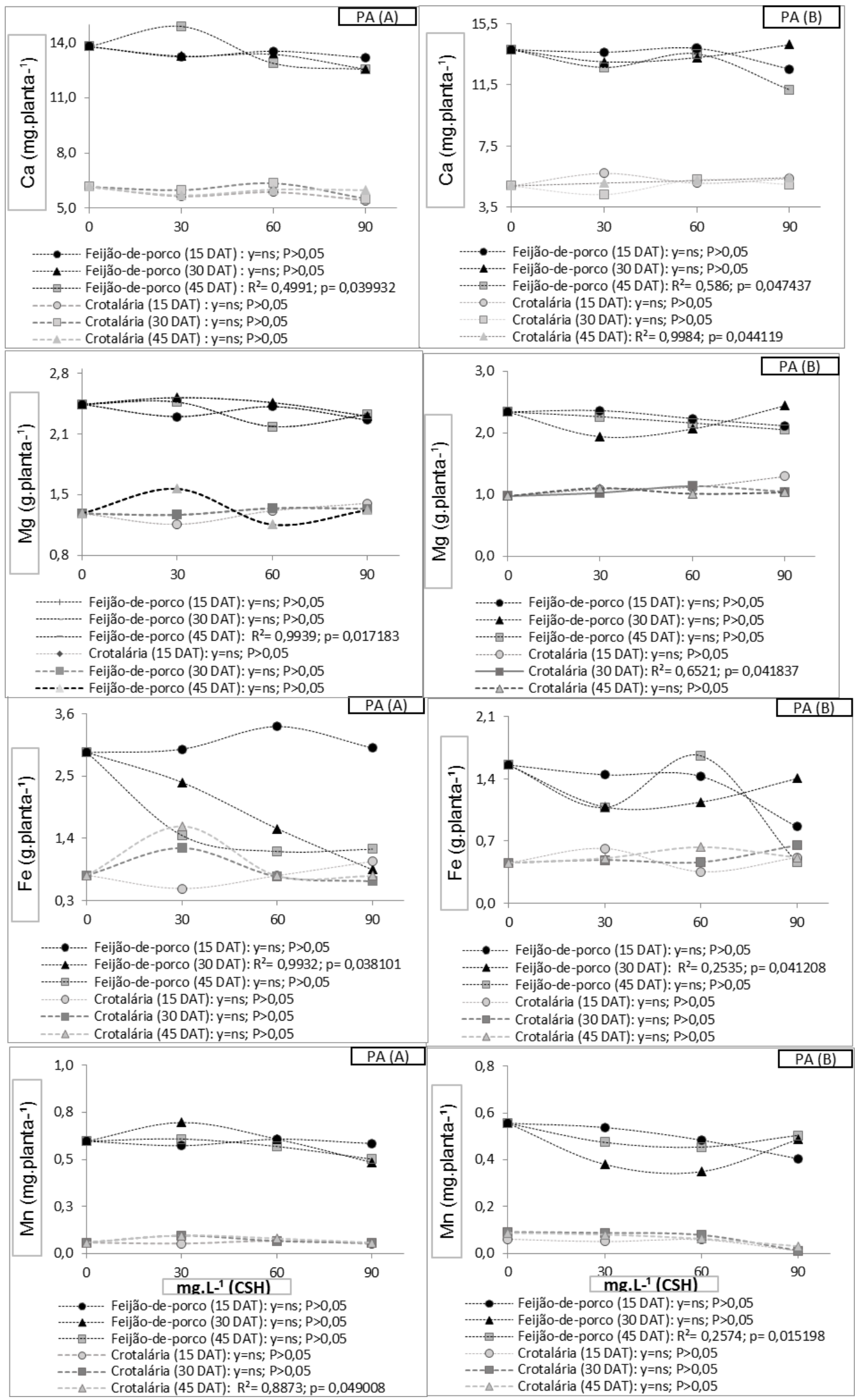

A aplicação de SH nas plantas de feijão-depara o acúmulo de $\mathrm{N}$, em que a dose 60 porco inoculadas apresentou resposta quadrática promoveu maior acumulação. Já nas plantas não- 
inoculadas de feijão-de-porco e crotalária, os maiores acúmulos de $\mathrm{N}$ foram obtidos com a dose 30 de SH fornecida aos 45 DAT. As plantas de crotalária inoculadas apresentaram resposta crescente positiva para o acúmulo de $\mathrm{N}$ com o fornecimento de $\mathrm{SH}$ aos 30 ou 45 DAT.

$\mathrm{O}$ acúmulo de $\mathrm{P}$ nas plantas de crotalária inoculadas e não-inoculadas apresentou resposta linear crescente com o fornecimento de $\mathrm{SH}$ aos 15 DAT. Para o acúmulo de $\mathrm{Ca}$, o feijão-de-porco não inoculado apresentou resposta linear decrescente com o fornecimento de $\mathrm{SH}$ aos 45 DAT, e as plantas de crotalária inoculadas apresentaram resposta linear crescente com 0 fornecimento de $\mathrm{SH}$ aos 45 DAT.

Segundo Freitas et al. (2018), as SH atuam como estimuladores da absorção de nutrientes por alterarem o metabolismo vegetal, com efeitos semelhantes aos fito-hormônios (FAÇANHA et al., 2002). As diferentes doses de $\mathrm{SH}$ em união com a temperatura e disponibilidade hídrica podem promover estresses fisiológicos nas plantas, além de aumentar ou reduzir o acúmulo de nutrientes nos estágios fenológicos que ocorrem em diferentes épocas estimulados pelas $\mathrm{SH}$.

A aplicação de substâncias húmicas em plantas é estudada e com uso recomendado para incremento no acúmulo de nutrientes em diversas culturas (MARTINS, 2017; AZAM SHAH et al., 2016; BUSATO et al., 2016; SANTOS et al., 2014).

O acúmulo de $\mathrm{Mg}$ apresentou resposta linear crescente em plantas de crotalária nos tratamentos em que as $\mathrm{SH}$ foram fornecidas aos 30 DAT, e resposta linear decrescente em plantas de feijão-de-porco não-inoculadas com fornecimento de SH aos 45 DAT. Em relação ao acúmulo de $\mathrm{Fe}$, plantas de feijão-de-porco inoculadas e não-inoculadas apresentaram resposta linear decrescente com o fornecimento de SH aos 30 DAT. Ademais, o fornecimento de $\mathrm{SH}$ aos 45 DAT promoveu resposta linear decrescente para o acúmulo de Mn por plantas de feijão-de-porco não-inoculadas e, nesta mesma época, promoveu o maior acúmulo de $\mathrm{Mn}$ por plantas de crotalária inoculadas com a dose $30 \mathrm{mg} \mathrm{L}^{-1}\left(\mathrm{C}_{\mathrm{SH}}\right)$.

Os presentes resultados evidenciam a importância da inoculação de bactérias diazotróficas e aplicação de SH na nutrição vegetal, pois além de $\mathrm{N}$, as plantas podem aumentar a extração de outros nutrientes, e o manejo adequado para certa finalidade se destaca quando o objetivo visa o acúmulo e ciclagem de um nutriente em específico.

A maior absorção e mobilização de nutrientes na parte aérea das plantas é desejável, por potencializar a ciclagem de nutrientes no meio e, desta forma, a alta capacidade de extração e eficiência no uso de $\mathrm{K}, \mathrm{Ca}, \mathrm{Mg}, \mathrm{P}$, Fe e $\mathrm{Mn}$ proporcionado pelos diferentes tratamentos interferem no balanço, fator de transferência e índice de translocação de nutrientes do rejeito.

O balanço, o fator de transferência e o índice de translocação de nutrientes do feijão-de-porco e crotalária comprovaram os efeitos distintos entre as espécies vegetais cultivadas quanto à extração de nutrientes do rejeito, devido a maior exigência por cada planta e diferentes processos que ocorrem na rizosfera para maior aproveitamento dos nutrientes (CASALI et al., 2016). Ademais, ressalta-se que na maioria dos casos as diferentes épocas de aplicação das $\mathrm{SH}$ não promoveram alterações $(p<0,05)$ nos índices de absorção de nutrientes e, por esta razão, os dados médios apresentados são dos tratamentos em que as SH foram fornecidas aos 30 DAT.

Em relação ao balanço de nutrientes (Tabela 2), nos tratamentos que não receberam $\mathrm{SH}, \mathrm{a}$ inoculação aumentou a absorção de $\mathrm{Fe}$ e $\mathrm{P}$ por plantas de feijão-de-porco, e nas plantas de crotalária aumentou a absorção de Mg, P e Mn e reduziu a absorção de Fe.

A alta porcentagem de extração de $\mathrm{K}$ se deve a baixa disponibilidade deste nutriente, mesmo com seu alto conteúdo no rejeito de minério de ferro utilizado nesta pesquisa. Contudo, cabe destacar que a crotalária apresentou maior extração de $\mathrm{K}$, evidenciando a capacidade de formas não trocáveis de $\mathrm{K}$ participarem do suprimento desta planta (ROSOLEM et al., 2012). $\mathrm{Em}$ análise geral e independente dos experimentos, a crotalária apresentou, de forma destacada, maior capacidade de extração do $\mathrm{K}$ estrutural do rejeito, e o feijoeiro apresentou maior capacidade de extração de $\mathrm{Ca}$ e $\mathrm{Mg}$. 
Tabela 2. Balanço de nutrientes após cultivo de Feijão-de-porco e Crotalária com ou sem inoculação de bactérias diazotróficas e cultivadas em rejeito de minério de ferro em função da aplicação de diferentes doses de substâncias húmicas fornecidas aos 30 dias após o transplantio.

\begin{tabular}{|c|c|c|c|c|c|c|c|}
\hline \multirow{2}{*}{\multicolumn{2}{|c|}{ Tratamento }} & K & $\mathrm{Ca}$ & Mg & $\mathrm{P}$ & $\mathrm{Fe}$ & $\mathrm{Mn}$ \\
\hline & & \multicolumn{6}{|c|}{ Balanço de nutrientes \% } \\
\hline Inoculação & $\mathrm{C}_{\mathrm{SH}}\left(\mathrm{mgL}^{-1}\right)$ & & & Feijão-c & -porco & & \\
\hline \multirow{4}{*}{ Com } & 0,0 & $10,05 \pm 1,72$ & $3,38 \pm 0,29$ & $1,41 \pm 0,13$ & $3,42 \pm 0,56$ & $6,79 \pm 0,43$ & $0,92 \pm 0,08$ \\
\hline & 30,0 & $9,65 \pm 2,17$ & $3,60 \pm 0,26$ & $1,52 \pm 0,05$ & $2,75 \pm 0,28$ & $5,91 \pm 0,93$ & $0,97 \pm 0,11$ \\
\hline & 60,0 & $10,15 \pm 1,66$ & $3,51 \pm 0,25$ & $1,56 \pm 0,09$ & $2,70 \pm 0,27$ & $5,13 \pm 0,58$ & $1,09 \pm 0,10$ \\
\hline & 90,0 & $11,11 \pm 1,93$ & $3,32 \pm 0,22$ & $1,41 \pm 0,25$ & $2,68 \pm 0,15$ & $4,68 \pm 0,59$ & $0,86 \pm 0,06$ \\
\hline \multirow{4}{*}{ Sem } & 0,0 & $11,26 \pm 1,61$ & $3,53 \pm 0,27$ & $1,53 \pm 0,07$ & $2,46 \pm 0,19$ & $4,53 \pm 0,72$ & $0,81 \pm 0,08$ \\
\hline & 30,0 & $10,37 \pm 2,66$ & $3,66 \pm 0,49$ & $1,58 \pm 0,10$ & $2,58 \pm 0,24$ & $4,42 \pm 0,79$ & $0,77 \pm 0,05$ \\
\hline & 60,0 & $14,00 \pm 2,85$ & $3,42 \pm 0,43$ & $1,39 \pm 0,02$ & $2,10 \pm 0,12$ & $3,72 \pm 0,80$ & $0,58 \pm 0,03$ \\
\hline & 90,0 & $14,63 \pm 1,20$ & $3,62 \pm 0,29$ & $1,48 \pm 0,11$ & $2,35 \pm 0,22$ & $4,39 \pm 0,75$ & $0,76 \pm 0,09$ \\
\hline Inoculação & $\mathrm{C}_{\mathrm{SH}}\left(\mathrm{mgL}^{-1}\right)$ & \multicolumn{6}{|c|}{ Crotalária } \\
\hline \multirow{4}{*}{ Com } & 0,0 & $22,78 \pm 1,34$ & $1,31 \pm 0,15$ & $1,01 \pm 0,12$ & $2,71 \pm 0,07$ & $4,74 \pm 0,74$ & $0,16 \pm 0,02$ \\
\hline & 30,0 & $22,85 \pm 1,35$ & $1,43 \pm 0,05$ & $1,09 \pm 0,04$ & $3,39 \pm 0,32$ & $6,96 \pm 1,31$ & $0,25 \pm 0,03$ \\
\hline & 60,0 & $21,05 \pm 1,85$ & $1,44 \pm 0,09$ & $0,92 \pm 0,10$ & $2,81 \pm 0,22$ & $5,70 \pm 0,70$ & $0,23 \pm 0,02$ \\
\hline & 90,0 & $21,53 \pm 1,75$ & $1,30 \pm 0,17$ & $0,96 \pm 0,13$ & $2,87 \pm 0,26$ & $4,86 \pm 0,57$ & $0,15 \pm 0,03$ \\
\hline \multirow{4}{*}{ Sem } & 0,0 & $20,86 \pm 1,52$ & $1,08 \pm 0,21$ & $0,79 \pm 0,11$ & $2,40 \pm 0,14$ & $6,15 \pm 0,05$ & $0,13 \pm 0,02$ \\
\hline & 30,0 & $23,27 \pm 2,94$ & $1,09 \pm 0,23$ & $0,83 \pm 0,09$ & $2,64 \pm 0,18$ & $5,75 \pm 0,61$ & $0,11 \pm 0,02$ \\
\hline & 60,0 & $22,03 \pm 1,29$ & $1,31 \pm 0,21$ & $0,89 \pm 0,12$ & $2,66 \pm 0,17$ & $6,37 \pm 0,52$ & $0,10 \pm 0,01$ \\
\hline & 90,0 & $22,92 \pm 2,21$ & $1,22 \pm 0,08$ & $0,94 \pm 0,05$ & $2,78 \pm 0,14$ & $5,58 \pm 0,21$ & $0,15 \pm 0,03$ \\
\hline
\end{tabular}

$\mathrm{C}_{\mathrm{SH}}\left(\mathrm{mg} \mathrm{L}^{-1}\right): \mathrm{mg}$ de $\mathrm{C}$ na forma de substâncias húmicas por litro de solução. $\mathrm{BN}=$ acúmulo total de nutriente na planta do tratamento " $\mathrm{n}$ "/teor de nutriente no rejeito.

A inoculação em plantas de feijão-de-porco aumenta o fator de transferência de $\mathrm{P}$ e $\mathrm{Fe}$, e reduz o fator de transferência de $\mathrm{K}, \mathrm{Ca}$ e $\mathrm{Mg}$ (Tabela 3). Neste contexto, a inoculação permite a maior aquisição de $\mathrm{N}$ pelas leguminosas, mas de certa forma reduz o poder de extração de outros nutrientes, mesmo os que são de grande exigência.

Destaca-se ainda que as plantas de crotalária apresentaram elevado fator de transferência de $\mathrm{K}, \mathrm{P}$ e Fe, devido aos altos teores de nutrientes na parte aérea desta planta. Segundo Silva et al. (2017), a crotalária é eficiente na absorção de nutrientes, mesmo em solos pobres, superando teores de nutrientes em outras leguminosas e suprindo exigências nutricionais de plantas que serão cultivadas posteriormente e/ou em consórcio.
O índice de translocação de nutrientes (Tabela 4) indica onde os mesmos estão mais mobilizados nas plantas, uma vez que o excesso ou escassez afeta sua absorção e acumulação. Constatou-se que $\mathrm{K}, \mathrm{Ca}, \mathrm{Mg}$ e $\mathrm{P}$ de ambos os experimentos foram mobilizados majoritariamente na parte aérea, visto que grande parte dos processos metabólicos ocorrerem nas folhas demandando maior concentração nutricional (VIEIRA et al., 2013). O micronutriente $\mathrm{Fe}$, em grande disponibilidade no rejeito, foi mais acumulado nas raízes, mobilizados neste componente como estratégia para minimizar estresses provocados por seu excesso (EPSTEIN; BLOOM, 2007). 
Tabela 3. Fator de transferência de nutrientes após cultivo de Feijão-de-porco e Crotalária com ou sem inoculação de bactérias diazotróficas e cultivadas em rejeito de minério de ferro em função da aplicação de diferentes doses de substâncias húmicas fornecidas aos 30 dias após o transplantio.

\begin{tabular}{|c|c|c|c|c|c|c|c|}
\hline \multirow{2}{*}{\multicolumn{2}{|c|}{ Tratamento }} & $\mathrm{K}$ & $\mathrm{Ca}$ & $\mathrm{Mg}$ & $P$ & $\mathrm{Fe}$ & $\mathrm{Mn}$ \\
\hline & & \multicolumn{6}{|c|}{ Fator de transferência } \\
\hline Inoculação & $\begin{array}{c}\mathrm{C}_{\mathrm{SH}} \\
\left(\mathrm{mgL}^{1}\right)\end{array}$ & \multicolumn{6}{|c|}{ Feijão-de-porco } \\
\hline \multirow{4}{*}{ Com } & 0,0 & $35,39 \pm 5,64$ & $18,79 \pm 1,92$ & $7,47 \pm 0,45$ & $31,07 \pm 6,08$ & $90,51 \pm 16,36$ & $7,65 \pm 0,66$ \\
\hline & 30,0 & $41,23 \pm 5,02$ & $23,85 \pm 4,06$ & $9,65 \pm 0,97$ & $24,21 \pm 2,17$ & $79,81 \pm 20,08$ & $8,57 \pm 0,94$ \\
\hline & 60,0 & $52,96 \pm 13,06$ & $25,09 \pm 3,20$ & $11,02 \pm 1,36$ & $26,70 \pm 5,76$ & $77,64 \pm 9,38$ & $11,16 \pm 0,94$ \\
\hline & 90,0 & $45,28 \pm 7,57$ & $22,95 \pm 2,84$ & $9,97 \pm 1,15$ & $25,68 \pm 2,89$ & $68,27 \pm 8,78$ & $7,75 \pm 0,81$ \\
\hline \multirow{4}{*}{ Sem } & 0,0 & $77,78 \pm 3,64$ & $26,43 \pm 3,10$ & $11,77 \pm 1,20$ & $23,14 \pm 3,07$ & $57,26 \pm 13,96$ & $7,11 \pm 0,51$ \\
\hline & 30,0 & $39,46 \pm 8,24$ & $20,06 \pm 3,40$ & $9,43 \pm 1,90$ & $18,77 \pm 1,95$ & $45,63 \pm 8,19$ & $5,35 \pm 0,78$ \\
\hline & 60,0 & $55,94 \pm 16,96$ & $20,30 \pm 5,24$ & $8,89 \pm 2,34$ & $14,20 \pm 2,28$ & $42,87 \pm 7,80$ & $4,70 \pm 1,02$ \\
\hline & 90,0 & $58,30 \pm 5,12$ & $21,15 \pm 3,62$ & $9,02 \pm 1,31$ & $17,17 \pm 1,91$ & $48,39 \pm 12,08$ & $5,79 \pm 0,58$ \\
\hline Inoculação & $\begin{array}{c}\mathrm{C}_{\mathrm{SH}} \\
\left(\mathrm{mgL}^{1}\right)\end{array}$ & \multicolumn{6}{|c|}{ Crotalária } \\
\hline \multirow{4}{*}{ Com } & 0,0 & $515,57 \pm 83,59$ & $25,49 \pm 6,40$ & $27,65 \pm 8,20$ & $71,74 \pm 15,61$ & $185,35 \pm 51,85$ & $5,23 \pm 1,54$ \\
\hline & 30,0 & $780,32 \pm 77,66$ & $47,56 \pm 5,71$ & $50,35 \pm 9,19$ & $162,15 \pm 23,92$ & $520,72 \pm 182,61$ & $15,48 \pm 3,30$ \\
\hline & 60,0 & $619,54 \pm 46,19$ & $39,42 \pm 4,44$ & $31,73 \pm 5,43$ & $105,98 \pm 19,54$ & $329,50 \pm 60,21$ & $11,76 \pm 2,42$ \\
\hline & 90,0 & $548,20 \pm 67,86$ & $27,61 \pm 5,22$ & $32,99 \pm 6,76$ & $92,08 \pm 13,94$ & $271,01 \pm 51,29$ & $5,79 \pm 1,68$ \\
\hline \multirow{4}{*}{ Sem } & 0,0 & $625,68 \pm 123,50$ & $30,60 \pm 4,54$ & $25,10 \pm 2,71$ & $76,15 \pm 10,91$ & $240,37 \pm 54,68$ & $7,11 \pm 3,31$ \\
\hline & 30,0 & $1096,23 \pm 341,81$ & $49,79 \pm 8,05$ & $37,31 \pm 4,40$ & $123,53 \pm 28,85$ & $246,72 \pm 52,26$ & $6,89 \pm 1,92$ \\
\hline & 60,0 & $621,56 \pm 126,22$ & $36,87 \pm 10,58$ & $25,20 \pm 1,99$ & $76,84 \pm 3,96$ & $195,61 \pm 39,06$ & $4,45 \pm 2,37$ \\
\hline & 90,0 & $651,81 \pm 124,38$ & $33,13 \pm 3,81$ & $29,45 \pm 2,92$ & $86,29 \pm 7,57$ & $209,41 \pm 35,03$ & $6,84 \pm 2,55$ \\
\hline
\end{tabular}

$\mathrm{C}_{S H}\left(\mathrm{mg} \mathrm{L}^{-1}\right): \mathrm{mg}$ de $\mathrm{C}$ na forma de substâncias húmicas por litro de solução. $\mathrm{FT}=$ teor de nutriente na parte aérea do tratamento " $\mathrm{n}$ "/teor disponível de nutriente no rejeito.

Tabela 4. Índice de translocação de $\mathrm{K}, \mathrm{Ca}, \mathrm{Mg}, \mathrm{P}$, Fe e Mn após cultivo de Feijão-de-porco e Crotalária com ou sem inoculação de bactérias diazotróficas, cultivadas em rejeito de minério de ferro em função da aplicação de diferentes doses de substâncias húmicas fornecidas aos 30 dias após o transplantio.

\begin{tabular}{|c|c|c|c|c|c|c|c|}
\hline \multirow{2}{*}{\multicolumn{2}{|c|}{ Tratamento }} & K & $\mathrm{Ca}$ & $\mathrm{Mg}$ & $\mathrm{P}$ & $\mathrm{Fe}$ & $\mathrm{Mn}$ \\
\hline & & \multicolumn{6}{|c|}{ Índice de translocação } \\
\hline Inoculação & $\mathrm{C}_{\mathrm{SH}}\left(\mathrm{mgL}^{-1}\right)$ & & & Feijão-de & porco & & \\
\hline \multirow{4}{*}{ Com } & 0,0 & $11,27 \pm 2,10$ & $3,11 \pm 0,81$ & $3,40 \pm 0,40$ & $0,89 \pm 0,22$ & $0,15 \pm 0,15$ & $1,15 \pm 0,37$ \\
\hline & 30,0 & $4,00 \pm 1,41$ & $2,35 \pm 0,40$ & $2,18 \pm 0,47$ & $0,79 \pm 0,09$ & $0,15 \pm 0,04$ & $1,57 \pm 0,26$ \\
\hline & 60,0 & $5,81 \pm 1,28$ & $2,35 \pm 0,55$ & $2,40 \pm 0,39$ & $1,00 \pm 0,26$ & $0,09 \pm 0,02$ & $0,85 \pm 0,26$ \\
\hline & 90,0 & $5,87 \pm 1,81$ & $2,29 \pm 0,25$ & $2,23 \pm 0,21$ & $0,86 \pm 0,06$ & $0,06 \pm 0,01$ & $0,95 \pm 0,25$ \\
\hline \multirow{4}{*}{ Sem } & 0,0 & $3,88 \pm 0,95$ & $2,53 \pm 0,33$ & $2,24 \pm 0,37$ & $0,93 \pm 0,11$ & $0,11 \pm 0,02$ & $1,29 \pm 0,46$ \\
\hline & 30,0 & $20,11 \pm 11,20$ & $2,51 \pm 0,89$ & $2,02 \pm 0,42$ & $0,98 \pm 0,17$ & $0,08 \pm 0,01$ & $0,80 \pm 0,10$ \\
\hline & 60,0 & $14,44 \pm 8,52$ & $2,48 \pm 0,39$ & $2,06 \pm 0,45$ & $1,67 \pm 0,52$ & $0,10 \pm 0,03$ & $0,95 \pm 0,10$ \\
\hline & 90,0 & $3,64 \pm 0,90$ & $2,27 \pm 0,41$ & $1,81 \pm 0,38$ & $1,01 \pm 0,30$ & $0,11 \pm 0,02$ & $0,83 \pm 0,17$ \\
\hline Inoculação & $\mathrm{C}_{\mathrm{SH}}\left(\mathrm{mgL}^{-1}\right)$ & \multicolumn{6}{|c|}{ Crotalária } \\
\hline \multirow{4}{*}{ Com } & 0,0 & $2,63 \pm 0,29$ & $6,71 \pm 1,62$ & $1,24 \pm 0,06$ & $1,39 \pm 0,45$ & $0,05 \pm 0,01$ & $0,45 \pm 0,09$ \\
\hline & 30,0 & $3,10 \pm 0,05$ & $3,87 \pm 1,32$ & $1,31 \pm 0,42$ & $2,14 \pm 0,79$ & $0,06 \pm 0,02$ & $0,55 \pm 0,30$ \\
\hline & 60,0 & $3,25 \pm 0,42$ & $4,55 \pm 1,49$ & $1,83 \pm 0,37$ & $1,25 \pm 0,31$ & $0,04 \pm 0,01$ & $0,31 \pm 0,06$ \\
\hline & 90,0 & $3,14 \pm 0,44$ & $7,96 \pm 2,53$ & $1,72 \pm 0,35$ & $1,83 \pm 0,45$ & $0,04 \pm 0,01$ & $0,62 \pm 0,10$ \\
\hline \multirow{4}{*}{ Sem } & 0,0 & $2,82 \pm 0,19$ & $4,88 \pm 0,64$ & $1,29 \pm 0,20$ & $1,45 \pm 0,31$ & $0,02 \pm 0,01$ & $0,07 \pm 0,09$ \\
\hline & 30,0 & $2,43 \pm 0,12$ & $3,08 \pm 0,32$ & $1,08 \pm 0,27$ & $0,91 \pm 0,11$ & $0,02 \pm 0,01$ & $0,03 \pm 0,01$ \\
\hline & 60,0 & $3,24 \pm 0,36$ & $2,97 \pm 0,64$ & $1,38 \pm 0,09$ & $1,52 \pm 0,24$ & $0,02 \pm 0,01$ & $0,03 \pm 0,01$ \\
\hline & 90,0 & $2,69 \pm 0,40$ & $2,43 \pm 0,43$ & $1,13 \pm 0,22$ & $1,32 \pm 0,12$ & $0,03 \pm 0,01$ & $0,03 \pm 0,01$ \\
\hline
\end{tabular}

$\mathrm{C}_{\mathrm{SH}}\left(\mathrm{mg} \mathrm{L}^{-1}\right): \mathrm{mg}$ de $\mathrm{C}$ na forma de substâncias húmicas por litro de solução. IT = acúmulo de nutriente na parte aérea do tratamento " $n$ "/acúmulo de nutriente na raiz do tratamento " $n$ ". 
Nas plantas de feijão-de-porco, a inoculação aumenta $\mathrm{O}$ acúmulo de $\mathrm{K}$ na raiz, e $\mathrm{o}$ fornecimento de $\mathrm{SH}$ reduz o acúmulo de $\mathrm{K}$ neste componente. Destaca-se ainda que as doses 30 ou $60 \mathrm{mg} \mathrm{L}^{-1}$ de $C_{S H}$ nas plantas de feijão nãoinoculadas elevam o acúmulo de $\mathrm{K}$ nas raízes.

\section{Conclusões}

O fornecimento de substâncias húmicas ou bactérias diazotróficas elevam o patamar de produção de matéria seca de feijão-de-porco e crotalária, entretanto, o uso associado de ambos os bioestimulantes não apresenta efeito acumulado no incremento desta variável.

A aplicação de SH em plantas de feijão-deporco inoculadas promove aumento no acúmulo de $\mathrm{N}$, principalmente na dose de $60 \mathrm{mg} \cdot \mathrm{L}^{-1}$.

O aumento no acúmulo de nutrientes em plantas não-inoculadas de ambas as espécies se deu frente a aplicação de $30 \mathrm{mg} \cdot \mathrm{L}^{-1}$ de $\mathrm{SH}$ fornecida aos 45 DAT, evidenciando o efeito sinérgico entre dose, época e fornecimento deste bioestimulante para se obter maior fitoextração.

A inoculação em plantas de feijão-de-porco aumentou a absorção e fator de transferência de Fe e $\mathrm{P}$, e reduziu o fator de transferência de $\mathrm{K}, \mathrm{Ca}$ e $\mathrm{Mg}$, e nas plantas de crotalária aumentou a absorção de $\mathrm{Mg}$, P e Mn e reduziu a absorção de Fe.

$\mathrm{K}, \mathrm{Ca}, \mathrm{Mg}$ e $\mathrm{P}$ de ambas espécies foram mobilizados majoritariamente na parte aérea, e o alto teor de Fe no rejeito de mineração culminou com grande absorção e mobilização deste elemento nas raízes das plantas como alternativa para minimizar efeitos tóxicos causados por seu excesso.

\section{Agradecimentos}

À Coordenação de Aperfeiçoamento de Pessoal de Nível Superior (CAPES) pela concessão da bolsa; À Fundação de Amparo à Pesquisa do Espírito Santo (FAPES) e de Minas Gerais (FAPEMIG) (processo número APQ-03603-17) pelo financiamento do estudo.

\section{Referências}

ARAÚJO, F. S. de; MARTINS, S. V.; MEIRA NETO, J. A. A.; LANI, J. L.; PIRES, I. E. Florística da vegetação arbustivo-arbórea colonizadora de uma área degradada por mineração de caulim, em Brás Pires, MG. Revista Árvore, v. 29, n. 6, p. 983-992, 2005. https://doi.org/10.1590/S0100$\underline{67622005000600018}$
AZAM SHAH, S.; MOHHAMAD, W.; SHAHZADI, S. S.; ELAHI, R.; ALI, A., BASIR, A. A.; HAROOM, A. The effect of foliar application of urea, humic acid and micronutrients on potato crop. Iran Agricultural Research, v. 35, n. 1, p. 89-94, 2016. https://doi.org/10.22099/IAR.2016.3680

BUSATO, J. G; ZANDONADI, D. B.; SOUSA, I. M. de; MARINHO, E. B.; DOBBSS, L. B.; MÓL, A.L. Efeito do extrato húmico solúvel em água e biofertilizante sobre o desenvolvimento de mudas de Callophyllum brasiliense. Pesquisa Florestal Brasileira, v. 36, n. 86, p. 161-168, 2016. https://doi.org/10.4336/2016.pfb.36.86.1024

CASALI, C. A.; TIECHER, T.; KAMINSKI, J.; SANTOS, D. R. dos.; CALEGARI, A.; PICINN, R. Benefícios do uso de plantas de cobertura de solo na ciclagem de fósforo. In: TIECHER, T. Manejo e conservação do solo e da água em propriedades rurais no sul do Brasil: práticas alternativas de manejo visando a conservação do solo e da água. Rio Grande do Sul: UFRGS, 2016. p. 23-33.

EMBRAPA AGROBIOLOGIA. Base de dados de leguminosas. Brasília, DF: EMBRAPA, 2009. Disponível em:

http://www.cnpab.embrapa.br/leguminosas.

Acesso em: 10 jan. 2020.

EPSTEIN, E., BLOOM, A. J. Nutrição mineral de plantas: princípios e perspectivas. Londrina: Editora Planta, 2007. 251-286 p.

FAÇANHA, A. R.; FAÇANHA, A. L. O.; OLIVARES, F. L.; GURIDI, F.; SANTOS, G. de A.; VELLOSO, A. C. X.; RUMJANEC, V. M.; BRASIL, F.; SCHRIPSEMA, J.; BRAZ-FILHO, R.; OLIVEIRA, M. A. de; CANELLAS, L. $P$. Bioatividade de ácidos húmicos: efeitos sobre o desenvolvimento radicular e sobre a bomba de prótons da membrana plasmática. Pesquisa Agropecuária Brasileira, v. 37, n. 9, p. 1301-1310, $2002 . \quad$ https://doi.org/10.1590/S0100$\underline{204 \times 2002000900014}$

FREITAS, G. A. de; WEBER, F.; SANTOS, A. C. M. Fertiacty ${ }^{\circledR}$ pós na redução da fitotoxidez do herbicida roundup ready ${ }^{\circledR}$ na cultura da soja. Revista em Agronegócio e Meio Ambiente, v. 11, n. 1, p. 99-116, 2018. http://doi.org/10.17765/21769168.2018v11n1p99-116 
HUNGRIA, M.; NOGUEIRA, M. A. Efeitos da coinoculação. Cultivar Grandes Culturas, PelotasRS, v. 170, n. 1, p. 40-41, 2013.

HUNGRIA, M.; NOGUEIRA, M. A.; ARAUJO, R. S. Co-inoculation of soybeans and common beans with rhizobia and azospirilla: strategies to improve sustainability. Biology and Fertility of Soils, v. 49, n. 7, p. 791-801, 2013.

https://doi.org/10.1007/s00374-012-0771-5

MALAVOLTA, E. Elementos de nutrição mineral de plantas. São Paulo: Ceres, 1980. 251 p.

MARTINS, J. D. L. Nutrição mineral e produtividade da cultura da batata em função da aplicação de substância húmica e adubação fosfatada. 2017. $124 \mathrm{f}$. Tese (Doutorado em Agronomia) - Universidade Estadual Paulista, Faculdade de Ciências Agronômicas, Botucatu, 2017.

MENDONÇA, E. S.; MATOS, E. D. S. Matéria orgânica do solo: métodos de análises. Viçosa: UFV, 2005. $77 \mathrm{p}$.

NEVES, A. L. R.; LACERDA, C. F. de; GUIMARÃES, F. V. A.; HERNANDEZ, F. F. F.; SILVA, F. B. da; PRISCO, J. T.; GHEYI, H. R. Acumulação de biomassa e extração de nutrientes por plantas de feijão-de-corda irrigadas com água salina em diferentes estádios de desenvolvimento. Ciência Rural, v. 39, n. 3, p. 758-765, 2009.

https://doi.org/10.1590/S010384782009005000014

OLIVEIRA, P. A. D. Adubação orgânica e emissões de gases de efeito estufa na recuperação de barragem de rejeito de beneficiamento de minério de ferro. 2014. 97 f. Dissertação (Mestrado em Solos e Nutrição de Plantas) Universidade Federal de Viçosa, 2014.

ORTEGA, A. E.; MALAVOLTA, E. Los más recientes micronutrientes vegetales. Informaciones Agronómicas de Hispanoamérica, Georgia, n.7, p. 16-25, 2012.

PADOVAN, M. P.; CARNEIRO, L. F.; MOITINHO, M. R.; FELISBERTO, G.; CARNEIRO, D. N. M.; MOTTA, I. de S. Acúmulo de Fitomassa e Nutrientes e Estádio mais Adequado de manejo do feijão- guandu para fins de adubação verde. Cadernos de Agroecologia, v. 9, n. 4, p.183-190, 2015.

PREZOTTI, L. C.; GOMES, J. A.; DADALTO, G. G.; OLIVEIRA, J. A. Manual de recomendação de calagem e adubação para o Estado do Espírito Santo. 5. ed. Vitória: SEEA/Incaper/Cedagro, 2007. $305 \mathrm{p}$.

R CORE TEAM: a language and environment for statistical computing. Vienna: R Foundation for Statistical Computing, 2016.

RODRIGUES, L. F.; GUIMARÃES, V. F.; SILVA, M. B. da; PINTO JUNIOR, A. S.; KLEIN, J.; COSTA, A. C. P. R. Características agronômicas do trigo em função de Azospirillum brasilense, ácidos húmicos e nitrogênio em casa de vegetação. Revista Brasileira de Engenharia Agrícola e Ambiental, v. 18, n. 1, p. 31-37, 2014.

https://doi.org/10.1590/S1415-

$\underline{43662014000100005}$

ROSOLEM, C. A.; VICENTINI, J. P. T. M. M.; STEINER, F. Suprimento de potássio em função da adubação potássica residual em um Latossolo Vermelho do Cerrado. Revista Brasileira de Ciência do Solo, v. 36, n. 5, p. 1507-1515, 2012. https://doi.org/10.1590/s0100$\underline{06832012000500015}$

SALA, V. M. R.; FREITAS, S. S.; SILVEIRA, A. P. D. Interação entre fungos micorrízicos arbusculares e bactérias diazotróficas em trigo. Pesquisa Agropecuária Brasileira, v. 42, n. 11, p. 15931600, 2007. https://doi.org/10.1590/S0100$\underline{204 \times 2007001100011}$

SANTOS, P. C.; SILVA, M. P. S.; FREITAS, S. J.; BERILLI, S. S.; ALTOÉ, J. A.; SILVA, A. de. A.; CARVALHO, A. J. C. Ácidos húmicos e brassinosteroide no crescimento e estado nutricional de rebentos de coroas de abacaxi. Revista Brasileira de Ciências Agrárias, v. 9, n. 4, p. 532-537, 2014. https://doi.org/10.5039/agraria.v9i4a4425

SANTOS, V. M.; DE MELO, A. V.; CARDOSO, D. P.; GONÇALVES A. H.; VARANDA, M. A. F.; TAUBINGER M. et al. Uso de bioestimulantes no crescimento de plantas de Zea mays L. Revista 
Brasileira de Milho e Sorgo, v. 12, n. 3, p. 307318, 2013. https://doi.org/10.18512/19806477/rbms.v12n3p307-318

SCHAEFER, C. E. G. R.; SANTOS, E. E.; SOUZA, C. M.; DAMATO NETO, J.; FERNANDES FILHO, E. I.; DELPUPPO, C. Cenário histórico, quadro físiográfico e estratégias para recuperação ambiental de Tecnossolos nas áreas afetadas pelo rompimento da barragem do Fundão, Mariana, MG. In: ARQUIVOS DO MUSEU DE HISTÓRIA NATURAL E JARDIM BOTÂNICO - UFMG. Belo Horizonte: UFMG, 2015. p. 104-135.

SILVA, L. R.; GUIMARÃES, M. C.; FREITAS, R. J.; PELÁ, A.; CARVALHO, D. D. C. Ácidos húmicos para obtenção de maior massa fresca inicial em plantas de feijão comum 'Pérola'. Revista Verde de Agroecologia e Desenvolvimento Sustentável, v. 11, n. 2, p. 06-10, 2016.

https://doi.org/10.18378/rvads.v11i2.3936

SILVA, M. S.; OLIVEIRA, G. R. F.; MERLOTI, M. E.; SÁ, M. E. Acúmulo de nutrientes e massa seca produzida por Crotalaria juncea cultivada no cerrado. Revista Brasileira de Engenharia de Biossistemas, v. 11, n. 1, p. 26-36, 2017. http://dx.doi.org/10.18011/bioeng2017v11n1p26 $\underline{-36}$

SILVA, L. C. R.; CORRÊA, R. S. Sobrevivência e crescimento de seis espécies arbóreas submetidas a quatro tratamentos em área minerada no cerrado. Revista Árvore, v. 32, n. 4, p. 731-740, 2008. https://doi.org/10.1590/S0100$\underline{67622008000400015}$

TEIXEIRA, P. C.; DONAGEMMA, G. K.; FONTANA, A.; TEIXEIRA, W. G. Manual de métodos de análise de solo. Rio de Janeiro: Embrapa, 2017. $573 \mathrm{p}$.

VACCARO, S.; ERTANI, A.; NEBBIOSO, A.; MUSCOLO, A.; QUAGGIOTTI, S.; PICCOLO, A.; NARDI, S. Humic substances stimulate maize nitrogen assimilation and amino acid metabolism at physiological and molecular level. Chemical and Biological Technologies in Agriculture, v. 2, n. 1, p. 1-12, 2015.

https://doi.org/10.1186/s40538-015-0033-5

VIEIRA, M.; SHUMACHER, M. V.; TRUBY, P.; ARAUJO, E. F. Biomassa e nutrientes em um povoamento de Eucalyptus urophylla $x$
Eucalyptus globulus, em Eldorado do Sul-RS. Revista Ecologia e Nutrição Florestal-ENFLO, v. 1, n. 1, p. 1-13, 2013. http://doi.org/10.13086/2316-980x.v01n01a01 